Revista de Antropología Social

ISSN: 1131-558X

http://dx.doi.org/10.5209/RASO.61849

\title{
Biotecnologías, mercados reproductivos y co-producción de parentesco
}

[en] Biotechnologies, reproductive markets and kinship co-production

Ana $\mathrm{M}^{\mathrm{a}}$ Rivas y Consuelo Álvarez ${ }^{1}$

Si hasta hace unas décadas, para los especialistas en el estudio del parentesco era de obligado cumplimiento citar a Schneider (1980) y su estudio sobre el parentesco euroamericano, en el que denunciaba la universalización del modelo biogenético y coitocentrista de las sociedades occidentales - que asocia la sexualidad a la reproducción, la reproducción a la heterosexualidad, la heterosexualidad al matrimonio, el matrimonio a la familia y la familia al modelo conyugal, heterosexual y biparental-, actualmente estudiar la formación de familias a través de las técnicas de reproducción asistida (TRA) y, particularmente, la formación de familias con la intervención de «terceros», sin citar a Thompson (2005) y su concepto de ontological choreography of reproductive technologies, traducido en castellano como «coreografía», resulta muy difícil. El éxito que ha tenido este concepto entre los investigadores se debe a su potencial analítico para abordar la complejidad que se deriva de la utilización de las tecnologías reproductivas en las que intervienen una pluralidad de agentes con lógicas, intereses y expectativas muy diferentes - «donantes $\rangle^{2}$, gestantes por sustitución $^{3}$, padres/madres intencionales, profesionales de la biomedicina, la psicología y el derecho, agencias transnacionales, clínicas, bancos de gametos y una pléyade de profesiones que han surgido en torno a la captación, seguimiento y mediación entre las familias receptoras y los/as trabajadores/as reproductivas- y una variada tipología de instituciones y marcos legislativos que prohíben, regulan o mantienen en

Universidad Complutense de Madrid, rivasant@ucm.es; coalvarez@ucm.es

2 El término «donantes» va entrecomillado porque es el utilizado en los discursos dominantes del aparato biomé$\mathrm{dico} /$ legal y reproducido por las mujeres y los hombres proveedores de biomateriales - gametos-y por las familias que acceden a estos tratamientos heterólogos, es decir, con material biogenético de «terceros». El término es sustituido aquí por proveedores y proveedoras reproductivas, incluyendo a las gestantes por sustitución, si bien deberíamos empezar a plantearnos otro concepto como el de «trabajadores/as reproductivas»; si hablamos de bioeconomía reproductiva, mercados reproductivos, industria de la (in)fertilidad, justo es hablar de estos «terceros», que participan en la generación de descendencia para otros, como trabajadores/as, lo que visibilizaría su contribución y las condiciones en las que realizan su trabajo.

3 Dada la polémica en torno a la forma de nombrar la gestación para otros y no siendo este el espacio para analizarla, hemos optado por este término que es el que se utiliza en la ley española 14/2006 sobre Técnicas de Reproducción Asistida. Para más información consultar el libro de Lamm (2013). 
la alegalidad algunas de estas prácticas reproductivas y reglamentan otros aspectos relativos a la provisión de gametos como el anonimato/no anonimato de los/as donantes, el altruismo/compensación económica de lo «donado», la selección de los/as proveedoras de gametos, el control y la gestión de la información identificativa y no identificativa de estos/as, los protocolos y consentimientos utilizados, la circulación transfronteriza de gametos y gestantes, etc.

La complejidad de estas técnicas de procreación con «terceras partes», no solo viene dada por la multiplicidad de actores individuales e institucionales que intervienen en ellas, sino por las posiciones desiguales y asimétricas de poder que ocupan en la estructura del campo de la reproducción ${ }^{4}$, resultado de la desigual posesión y distribución de capitales. Precisamente, esas «terceras partes», imprescindibles para satisfacer el deseo de paternidad y maternidad de muchos hombres y mujeres, permanecen silenciadas y arrojadas a los márgenes de los debates públicos, salvo cuando representan una ocasión para el sensacionalismo mediático y oportunismo político, tal y como está ocurriendo actualmente en España con la gestación por sustitución; debate totalmente descontextualizado, al tratarlo como si fuera una práctica aislada y desconectada de las estructuras económicas, políticas, jurídicas, sociales y culturales que subyacen a las TRA y a todas las TRA, incluyendo la provisión de óvulos, semen y embriones. Esta polémica se mantiene encerrada en torno a la gestación subrogada, sin que se enmarque en el contexto más general del sistema de reproducción asistida y de provisión de material reproductivo en España, y sin que se tenga en cuenta las perspectivas, entre otros, de los/as proveedores/as reproductivas. Pensamos que este marco general de comprensión de cada uno de los tratamientos de reproducción asistida heteróloga es básico para poder tomar decisiones sobre las implicaciones de cada uno de ellos. Problematizar la subrogación en España sin problematizar al mismo tiempo el sistema de reproducción asistida con donantes (anonimato/no anonimato, selección de los/as donantes, mercantilización/altruismo, exclusión de la seguridad social, etc.) supone dejar fuera cuestiones fundamentales como la equidad/ inequidad en el acceso de las familias a las TRA, la cosificación de los cuerpos no solo de las gestantes sino de los/as proveedores/as de gametos, el control y el monopolio de ciertos agentes intermediarios sobre el proceso (Igareda, 2015).

La estratificación socioeconómica de los mercados reproductivos afecta a los/ as proveedoras de material biogénético, estableciendo una biojerarquización entre países enriquecidos- países empobrecidos, pero también al interior de los primeros en razón de su origen social, étnico, educativo, etc. Esta estratificación también se da entre las familias que desean acceder a las TRA para conseguir descendencia, dado que sus costes no están al alcance de todas. En el caso de España, con un salario mínimo interprofesional de 735 euros y una compensación económica entre 900 y 1.100 euros por ciclo de «donación» de óvulos, se entiende el aumento de la oferta de óvulos por parte de mujeres desempleadas o con trabajos asalariados en sectores escasamente cualificados y altamente precarizados ${ }^{5}$. Pero también se entiende el perfil

4 Utilizamos aquí el concepto «estructura del campo» de Bourdieu «[...] la estructura del campo definida por la distribución desigual del capital, es decir, de las armas (o de las bazas) específicas, influye, al margen de cualquier intervención o manipulación directa, sobre el conjunto de los agentes implicados en el campo al restringir el espacio de los posibles que se abre ante ellos tanto más cuanto peor colocados están en esa distribución». (2003: 240).

5 Sin pretender generalizar ni extrapolar a todas las proveedoras de óvulos en España, este es el perfil dominante en los resultados del proyecto de investigación «Familias, Centros de reproducción asistida y donantes. Miradas 
de las familias que pueden acceder a estos tratamientos y que, una vez agotadas las opciones en el sistema público, se distribuyen entre clínicas y países en función de sus ingresos y los costes de los tratamientos, situándose en una escala de seguridad/ inseguridad jurídica acorde con sus posibilidades económicas, al mismo tiempo que se expulsa a otras familias de estos mercados por falta de ingresos suficientes ${ }^{6}$.

Con este número de la RAS pretendemos contribuir al debate en torno a las TRA desde una perspectiva interdisciplinar-socioantropológica, política y jurídica-como requiere el carácter multidimensional del fenómeno. Los artículos de este número monográfico son resultado de investigaciones que se centran fundamentalmente en 1) las implicaciones socioculturales, políticas, económicas y jurídicas que tiene la participación de «terceros» en la co-producción de familias y parentesco; 2) la construcción de las subjetividades de los/as trabajadores/as reproductivas, la concepción y valoración del acto de su «donación», así como 3) los contextos estructurales que dan sentido a sus prácticas y discursos desde las posiciones que en ellos ocupan respecto al resto de actores (familias receptoras, clínicas, bancos de gametos, agencias de intermediación, etc.).

Pese a la potencialidad que representa España en la industria reproductiva y, especialmente, en la provisión de gametos, llama la atención la escasa producción científica y, por tanto, el escaso conocimiento que se tiene de la versión de los/as proveedoras de gametos, las familias receptoras y la descendencia concebida a través de la reproducción heteróloga, comparado con la literatura internacional. Esto explica el tipo, nivel y contenido de los debates en España, en los que todo el mundo parece tener algo que decir, excepto los/as protagonistas del fenómeno, quienes hacen posible la provisión de material biogenético. Revisar y contrastar la escasa bibliografía existente en España con la bibliografía internacional mucho más abundante, es el objetivo del texto de Ana $\mathrm{M}^{\mathrm{a}}$ Rivas, Consuelo Álvarez y M $\mathrm{M}^{\mathrm{a}}$ Isabel Jociles, con el que se inicia este monográfico.

Los textos de Noelia Igareda, Diane Tober y Vincenzo Pavone, y Mariana Viera, analizan los discursos y las prácticas dominantes del establishment biomédico, jurídico y económico sobre la «donación» de óvulos como «donación de vida» y los dispositivos políticos, jurídicos, económicos y sociales que se utilizan para legitimar el acceso a los biomateriales de las proveedoras de óvulos y la biojerarquización resultante de los procesos de captación y selección de estas últimas. El análisis se aborda desde una perspectiva interdisciplinar, el derecho, la sociología, las políticas públicas y la antropología. Desde el enfoque jurídico, Noelia Igareda se centra en la diversidad legal existente en Europa acerca de la donación de óvulos y el anonimato,

cruzadas. Variaciones según modelos familiares y anonimato/no anonimato de la donación», financiado por el Ministerio de Economía y Competitividad. Plan Nacional I+D+i. CSO2015-64551-C3-2-R, del que son IPs las coordinadoras de este monográfico.

6 Como muestra de los costes de las TRA en España sirvan estos datos extraídos de una página web de una clínica de la Comunidad Autónoma de Madrid: Inseminación artificial con los espermatozoides de la pareja (380€); Inseminación artificial con semen de donante (705€); Fecundación in vitro con los óvulos propios y espermatozoides de la pareja (2.350€); Fecundación in vitro mediante la inyección intracitoplasmática, selección de uno de los espermatozoides activos y sin anomalías, que posteriormente se introduce en el óvulo a fecundar mediante una microinyección (2.850€); Fecundación in vitro con óvulos de donante (3.680€); Fecundación in vitro con donante de semen (2.675€); Adopción de embriones donados por sus progenitores biológicos (1.500€); Transferencia de embriones propios (650€); Vitrificación y crioconservación de los propios óvulos para disponer de ellos cuando se desee buscar un embarazo futuro (2.280€) https://easyfiv.es/ (Página web consultada el 28/09/2018) 
que ha facilitado el llamado «turismo reproductivo» y ha convertido a España en uno de los destinos reproductivos más buscados. Al mismo tiempo aborda los problemas suscitados por el altruismo de la «donación» y las posibles situaciones de explotación de mujeres que cuestionan este discurso de «donar vida».

Diane Tober y Vincenzo Pavone, desde la sociología y las políticas públicas, se interesan por cómo los sistemas reguladores que controlan la reproducción con «terceros» determinan los procesos de selección y compensación/pago de las personas que proveen de material biogenético a los mercados reproductivos y cómo diferentes bioeconomías influyen en la mayor o menor biodisponibilidad de unas mujeres sobre otras en el mercado de óvulos. Para ello, comparan la provisión de óvulos en un sistema público/privado que regula y permite la compensación económica como es el caso de España, con un sistema médico no regulado de libre mercado como Estados Unidos.

Mariana Viero, antropóloga, se centra en la economía moral de la donación de gametos para intervenciones biotecnológicas con objetivos reproductivos en Uruguay, especialmente en dos asuntos disputados en el marco de esta economía moral: la adecuación o inadecuación de los procedimientos de acceso a ovocitos de donación y las maneras legítimas de retribuir la donación de gametos. Con el análisis de la economía moral de la donación de gametos busca problematizar los valores atribuidos a las biologías sexuadas en el contexto de esta bioeconomía y cómo estos valores inciden en las prácticas y discursos de la donación. Concluye sobre la laxitud moral que acompaña la economía de la donación en Uruguay, en lo que tiene que ver con las personas donantes de ovocitos, a pesar de los riesgos clínicos concretos que tiene el proceso sobre estas.

Junto a las proveedoras de óvulos, otro colectivo de mujeres que intervienen en la reproducción con «terceros» son las gestantes por sustitución, de las que todo el mundo se siente con derecho a opinar y hablar en su nombre, pero cuya perspectiva y punto de vista apenas se conoce. $\mathrm{M}^{\mathrm{a}}$ Eugenia Olavarría, a través de una investigación etnográfica en tres ciudades mexicanas entre trabajadoras/es de la donación reproductiva, realizado durante el periodo más álgido de la polémica surgida en torno a la regulación prohibitiva del Senado de la República de la práctica de la gestación subrogada (2015-2017), permite conocer a estos actores -trabajadoras/es reproductivos- y mostrar así, cómo las funciones de la donación y de la intermediación, de la gestante, de la ovodonante y de la intermediaria o bróker se articulan de manera inédita, revelando discursos, prácticas y significados vigentes, y al mismo tiempo cambiantes, de las coreografías de la reproducción asistida y de los parentescos en México.

Rosanna Hertz en su investigación sociológica sobre los donantes de semen en Estados Unidos aborda otro de los temas más problemáticos en la reproducción heteróloga: el anonimato/no anonimato de los proveedores de gametos. Desde la experiencia estadounidense que permite a los proveedores de semen elegir entre anónimo y no-anónimo, Hertz indaga sobre cómo los donantes toman esta decisión, qué piensan acerca de su donación y la descendencia que imaginan haber podido tener, o la posibilidad de cambiar su opinión sobre su anonimato. A partir de datos provenientes de varias fuentes, analiza la evolución de las narrativas de los donantes sobre ellos mismos como donantes y sobre su descendencia genética; especialmente, aquellos donantes que han cambiado de opinión -de anónimo a no-anónimo- ofrecen una oportunidad única para entender sus lógicas y las consecuencias que tiene este cam- 
bio para los padres y su descendencia, lo que permite una mejor comprensión del nuevo rol emergente de los donantes en las familias nucleares.

No se puede tratar el tema de las TRA con intervención heteróloga sin plantearse los desafíos y retos que representa para la mayoría de ordenamientos jurídicos sobre derecho familiar, anclados aún en el sistema cultural de parentesco biogenético y coitocéntrico, la emergencia de una «tercera parte» que resquebraja el sistema de filiación bilateral dominante. La experiencia de Argentina que presenta y analiza la jurista Marisa Herrera, integrante del equipo de redacción del Código Civil y Comercial de Argentina en vigencia desde el 01/08/2015, pone en evidencia la multiplicidad de problemáticas jurídicas derivadas de la irrupción de las TRA en el derecho filial: el reconocimiento de un tercer tipo filiatorio junto con el natural y adoptivo, bajo la noción de «voluntad procreacional»; qué acontece con la revocación en supuestos especiales como el fallecimiento y la ruptura de la unión; qué ocurre cuando se disocia voluntad procreacional de gestación por sustitución o cuando la voluntad procreacional es prestada por más de dos personas. Estos debates han centrado el escenario del derecho argentino contemporáneo; su abordaje, planteamientos y respuestas, desde la perspectiva de los derechos humanos, pueden servir de referente a otros países en los que el uso en aumento de las TRA heterólogas exige respuestas que contemplen la multiplicidad de actores que intervienen en el proceso con intereses y expectativas diferentes.

\section{Referencias bibliográficas}

Bourdieu, Pierre (2003). Las estructuras sociales de la economía. Barcelona: Anagrama. Igareda, Noelia (2015). «El derecho a conocer los orígenes biológicos vs el anonimato en la donación de gametos», comunicación presentada en el Workshop sobre Derechos reproductivos y reproducción asistida. Género, diversidad sexual y familias en plural, celebrado en el International Institute for the Sociology of Law, 30 Abril - 1 Mayo 2015, en Oñati (Gipuzkoa).

Lamm, Eleonora (2013). Gestación por sustitución. Ni maternidad subrogada ni alquiler de vientres. Barcelona: Universitat de Barcelona, Publicacions i Edicions.

Schneider, David (1980). American Kinship. A cultural Account. Chicago: The University of Chicago Press.

Thompson, Charis (2005). Making Parents. The Ontological Choreography of Reproductive Technologies. Cambridge, MIT Press. 